\title{
Teste de Figuras para Discriminação Fonêmica: uma proposta
}

\author{
Phoneme Discrimination Picture Test: a proposal
}

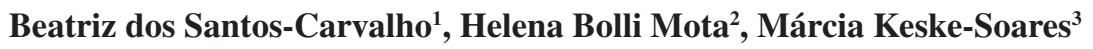

\begin{abstract}
RESUMO
Objetivos: Propor um teste que avaliasse a discriminação fonêmica por meio de pares mínimos, abrangendo todos os fonemas do Português Brasileiro e utilizando-os em palavras que possam ser facilmente representadas por figuras. Buscou-se que este teste contribua para o diagnóstico de alterações fonoaudiológicas e para a pesquisa científica. Procurou-se fazer um teste que fosse de fácil aplicação, podendo ser utilizado em qualquer local de trabalho dos fonoaudiólogos. Métodos: Selecionou-se pares mínimos que opusessem fonemas em relação ao valor binário de cada traço distintivo e às combinações possíveis entre os traços de lugar ([labial], [coronal], [dorsal]) bem como pelas oposições de estruturas silábicas. Criou-se figuras que representam as palavras dos pares. Resultados: Elaborou-se o Teste de Figuras para Discriminação Fonêmica, que avalia a habilidade de discriminação fonêmica em crianças de quatro a oito anos. Este teste contém 40 apresentações, das quais 30 são pares mínimos e dez pares de palavras iguais. Nestas 30 apresentações, opôs-se os traços distintivos [+/- soante], [+/- aproximante], [+/- contínuo], [+/- voz], [coronal+/-ant], [labial] x [coronal], [dorsal] x [coronal] e [labial] x [dorsal]. Igualmente foram opostas as seguintes estruturas silábicas: V x CV, CV x CCV, CV x CVC. Conclusão: Conclui-se que os objetivos deste trabalho foram alcançados com êxito, pois o Teste de Figura para Discriminação Fonêmica contempla tudo a que se propôs. Acredita-se que o teste deva ser aplicado em um estudo piloto para averiguar se as palavras e as figuras estão adequadas para a faixa etária. Posteriormente, deve ser aplicado em diversas regiões do país para ser devidamente padronizado.
\end{abstract}

DESCRITORES: Testes de discriminação da fala; Percepção da fala; Desenvolvimento da linguagem; Linguagem infantil; Transtornos do desenvolvimento da linguagem

\section{INTRODUÇÃO}

A discriminação fonêmica é muito importante para a aquisição da linguagem. É por meio da recepção, análise e organização do processamento das informações auditivas que se estabelece a representação mental do estímulo lingüístico e o armazenamento dessa representação na memória ${ }^{(1)}$.

Sendo a discriminação fonêmica um fator consideravelmente relevante no processo de aquisição normal da linguagem, deduz-se que, nas alterações da mesma, esta habilidade

Trabalho realizado no Curso de Mestrado em Distúrbios da Comunicação Humana do Departamento de Otorrino-Fonoaudiologia da Universidade Federal de Santa Maria - UFSM - Santa Maria (RS), Brasil.

(1) Pós-graduanda em Distúrbios da Comunicação Humana da Universidade Federal de Santa Maria - UFSM - Santa Maria (RS), Brasil.

(2) Doutora, Professora do Curso de Fonoaudiologia, da Especialização em Fonoaudiologia e do Curso de Mestrado em Distúrbios da Comunicação Humana da Universidade Federal de Santa Maria - UFSM - Santa Maria (RS), Brasil.

(3) Doutora, Professora do Curso de Fonoaudiologia, da Especialização em Fonoaudiologia e do Curso de Mestrado em Distúrbios da Comunicação Humana da Universidade Federal de Santa Maria - UFSM - Santa Maria (RS), Brasil.

Endereço para correspondência: Beatriz dos Santos Carvalho. R. das Petúnias, 227, Ouro Verde, Santa Rosa - RS, CEP 98900-000. E-mail: fgabeatriz@yahoo.com.br

Recebido em: 12/7/2007; Aceito em: 30/6/2008 pode estar alterada. Esta hipótese foi pesquisada em vários grupos de crianças, dentre os quais podemos citar pesquisas em crianças com Distúrbio Específico da Linguagem ${ }^{(2)}$; em crianças com Desvios Fonológicos Evolutivos ${ }^{(3-4)} \mathrm{e} e \mathrm{em}$ crianças de diferentes classes sociais ${ }^{(5)}$. Todos estes trabalhos encontraram alterações na habilidade de discriminação fonêmica/ discriminação auditiva nos grupos estudados.

$\mathrm{Na}$ literatura brasileira, encontrou-se apenas dois testes que avaliassem a habilidade de discriminação fonêmica: a Prova para Avaliar a Discriminação Auditiva ${ }^{(6)}$ e o Teste de Figuras para Discriminação Auditiva ${ }^{(7)}$.

A Prova para Avaliar a Discriminação Auditiva ${ }^{(6)}$ utiliza pares de sílabas contrastantes como estímulo, que a criança deve ouvir e dizer se são diferentes ou iguais. Esses pares diferenciam-se pelo traço de sonoridade (ex: be / pe) e pelo traço de nasalidade (ex: le / ne), pelo ponto de articulação (ex: gue / de) e pelo modo de articulação (ex: me / be). Estas diferenciações foram escolhidas pela evidência no trabalho clínico do autor do predomínio de dificuldades na comunicação oral relacionadas a sons com estas características ${ }^{(6)}$.

No total, a Prova para Avaliar a Discriminação Auditiva ${ }^{(6)}$ tem 30 pares de sílabas, dos quais 20 são constituídos por sílabas diferentes e dez por sílabas iguais. Inclui uma pré-prova, utilizada para verificar se a criança testada possui o conceito de igual/diferente e para explicar o que se espera de resposta. 
A apresentação dos estímulos é feita por intermédio de uma gravação, para padronização das apresentações e para evitar o uso de pistas visuais. Esta gravação é apresentada para a criança por meio de um gravador, sem uso de fones de ouvido.

O Teste de Figuras para Discriminação Auditiva ${ }^{(7)}$ é uma adaptação ao The Boston University Speech Sound Discrimination Picture Test e utiliza palavras (pares mínimos) como estímulo auditivo. Estes pares mínimos estão representados por figuras em cartelas. A criança testada deve ouvir o par de palavras e apontar para a cartela que tenha as figuras que representam o par ouvido. Os contrastes de fonemas, que aparecem nos pares mínimos do teste, foram escolhidos com base nas trocas mais comumente utilizadas pelas crianças com alterações na fala $^{(7)}$. A apresentação dos pares é feita à viva-voz, sendo que o avaliador deve esconder a boca na hora de falar para evitar o uso de pistas visuais. O teste totaliza 25 apresentações, sendo algumas de pares mínimos e outras de duas palavras iguais.

Esta adaptação apresenta algumas falhas, no que diz respeito à presença de todas as consoantes do Português Brasileiro, nas oposições dos pares mínimos; melhor distribuição das oposições de fonemas nas possibilidades de posições das sílabas nas palavras, escolha de palavras que façam parte do vocabulário infantil, adequação da figura utilizada à palavra que deveria representar e estabelecimento de padrões de normalidade para o teste.

Na língua portuguesa, há 26 fonemas segmentais, sendo 19 consoantes e sete vogais ${ }^{(8)}$. O sistema consonantal do português é formado por seis consoantes oclusivas: /p, b, t, d, k, g/, seis consoantes fricativas: /f, v, s, z, š, ž/, três nasais: /m, n, ñ/ e quatro líquidas: $/ \mathrm{l}, \Lambda, \mathrm{r}, \mathrm{R} /$.

Os fonemas podem ser subdivididos em unidades menores, chamadas traços distintivos, que são o conjunto de propriedades que caracterizam a sua produção ${ }^{(9)}$. Estes traços são as unidades mínimas que se unem para a composição de um segmento da língua (fonema), e podem identificar este fonema ou distingui-lo dos demais. Os traços distintivos têm três funções básicas: descrever as propriedades articulatórias e /ou acústicas que entram na composição do som, diferenciar itens lexicais e agrupar os sons em classes naturais ${ }^{(9)}$.

Para estudar a organização dos traços nas representações fonológicas foi proposta a Geometria de $\operatorname{Traços}^{(10)}$. De acordo com esta teoria, os segmentos são apresentados como configurações de nós, hierarquicamente organizados, cujos nós terminais são valores de traços e cujos nós intermediários representam constituintes. Os princípios básicos desta teoria são: regras fonológicas desempenham somente operações simples e a organização dos traços é universalmente determinada.

$\mathrm{Na}$ geometria de traços, utiliza-se um sistema binário para indicar características opostas, ou seja, usa-se apenas um traço distintivo antepondo a ele um sinal positivo (+) ou negativo (-), que indica se o tributo se faz presente ou não ${ }^{(8)}$. O sistema binário vale para todos os traços, com exceção dos traços dos articuladores que apresentam apenas um valor (sendo chamados privativos), pois não há regras fonológicas operando nos valores negativos destas categorias ${ }^{(8)}$. Os traços dos articuladores são: [labial], envolvendo os lábios como articulador ativo; [coronal], envolvendo a frente da língua como articulador ativo e [dorsal], envolvendo o corpo da língua como articulador ativo. $\mathrm{O}$ fato de ser usado um sistema binário de representação dos traços distintivos indica que os traços são abstrações - idealizações de capacidades articulatórias e acústicas dos fonemas.

Baseada na representação geométrica geral dos segmentos consonantais, foi proposta a Matriz Fonológica dos Segmentos Consonantais do Português ${ }^{(8)}$ que será a adotada neste trabalho. A representação geométrica considera um Nó de Raiz, com os traços [soante], [aproximante] e [vocóide]; um Nó Laríngeo, com o traço [voz]; um Nó de Cavidade Oral, com o traço [contínuo] e o Nó de Lugar de Consoante, com os traços [labial], [coronal] (a ele ligado o traço [anterior]) e [dorsal].

Pela escassez de testes que avaliam a discriminação fonêmica propostos para as crianças brasileiras, considerou-se necessária a criação de um instrumento de avaliação elaborado a partir do Português Brasileiro e devidamente padronizado para as crianças deste país. Este instrumento deve observar aspectos quantitativos e qualitativos durante a tarefa de discriminar as diferenças entre os fonemas e levar em consideração a adequação das palavras do teste ao vocabulário infantil e a escolha de figuras que representem fielmente as palavras a serem testadas.

Assim, esta pesquisa teve como objetivo propor um teste que avaliasse a discriminação fonêmica por meio de pares mínimos, escolhidos pelas oposições dos fonemas em relação ao valor binário de cada traço distintivo e às combinações possíveis entre os traços de lugar ([labial], [coronal], [dorsal]), e pelas oposições de estruturas silábicas, buscando que este teste contribua para o diagnóstico de alterações fonoaudiológicas e para a pesquisa científica nesta área.

\section{MÉTODOS}

Serão descritos nesta seção os procedimentos utilizados para a elaboração do Teste de Figuras para Discriminação Fonêmica - TFDF.

Buscou-se propor um teste que avaliasse a discriminação fonêmica por meio de pares mínimos. Estes pares mínimos foram escolhidos pelas oposições dos fonemas em relação ao valor binário de cada traço distintivo e as combinações possíveis entre os traços de lugar ([labial], [coronal], [dorsal]) bem como pelas oposiçõos de estruturas silábicas. Para isso, utilizou-se a Matriz Fonológica dos Segmentos Consonantais do Português Brasileiro ${ }^{(8)}$.

O TFDF destina-se a avaliar crianças de quatro a oito anos de idade. Para a escolha das palavras do TFDF, procedeu-se da seguinte forma: primeiro selecionou-se todos os traços distintivos que apresentavam oposições de valores binários e as combinações possíveis entre os traços de lugar, cruzandoos entre si. Depois verificou-se, dentro de cada combinação, quais eram os pares de fonemas que diferiam entre si pelo menor número de traços distintivos, objetivando encontrar pares de fonemas que diferissem entre si somente nos traços em questão. Os pares de fonemas que diferiam entre si pelo menor número de traços foram selecionados.

Depois de realizada a verificação das oposições dos traços bem como da representação destes por fonemas, passou-se para 
a escolha dos pares mínimos. Para esta escolha utilizaram-se os seguintes critérios: palavras que fossem facilmente representáveis por desenho, pares de palavras com os fonemas escolhidos em duas posições dentro das palavras (OI e OM), palavras monossilábicas seguidas de dissilábicas ou trissilábicas; palavras que fizessem parte do vocabulário de crianças com quatro anos de idade (idade mínima a que o teste se propõe a avaliar); palavras com diferentes estruturas silábicas (CV, CCV, CVC).

O objetivo do teste era avaliar a habilidade de discriminar auditivamente os fonemas, ou seja, avaliar a discriminação fonêmica da criança. No entanto, considerou-se importante acrescentar ao teste alguns pares de palavras que tivessem oposição não do fonema, mas da ordem em que estes aparecem nas palavras (estrutura silábica).

Optou-se pela elaboração de um teste de figuras, porque elas servem para auxiliar a memória das crianças e obter um instrumento lúdico ${ }^{(11)}$. Assim, no TFDF, a criança ouve as palavras dos pares mínimos, tendo à sua frente as cartelas do teste com as figuras que representam graficamente estas palavras, evitando-se assim que ela tenha que memorizar as palavras por mais tempo enquanto busca o acesso léxico destas palavras, para depois disto responder à apresentação.

Igualmente, com a utilização das figuras e disposição destas em cartelas, pôde-se obter um caráter lúdico no teste, fazendo com que a criança não sinta tensão por estar sendo avaliada e tenha prazer em responder as apresentações do teste.

Após decidir quais pares mínimos iriam fazer parte do teste, contratou-se um profissional das artes visuais para que criasse as figuras representativas das palavras. Este profissional fez os desenhos à mão livre e, em seguida, a autora conferiu os desenhos e solicitou algumas modificações. Então, os desenhos foram passados para o computador, coloridos e assumiram sua versão final.

Muitos testes fazem uso de itens de demonstração ${ }^{(6-7,11-12)}$, a serem utilizados antes da aplicação do teste em si, para explicar à criança testada como ela deve proceder nas tarefas. Acredita-se que o uso destes itens é de suma importância para o examinador e para a criança a ser avaliada. Assim, também o TFDF terá itens de demonstração.

Não foi encontrada na literatura revisada nenhuma referência ao tempo máximo ideal para testar uma criança. Acredita-se que este tempo aumente gradualmente com a idade da criança testada, e que o teste não deve ser demasiadamente longo, pois o cansaço da criança influenciará no seu desempenho.

Com base nesta premissa, procurou-se desenvolver um teste que não fosse extenso demais, mas que contemplasse exemplares de todas as oposições de fonemas seguindo a oposição de traços distintivos e de estruturas silábicas, conforme descrito anteriormente.

Considera-se importante impedir a presença de pistas visuais na apresentação dos estímulos, pois se sabe que a percepção visual auxilia na percepção da fala. Para que o examinador possa certificar-se de que a habilidade usada foi a discriminação fonêmica, com base somente no estímulo auditivo, o examinador deve utilizar o próprio Protocolo de Apresentação do TFDF para tapar a sua boca, impedindo que a criança veja os gestos articulatórios.
Durante a elaboração do TFDF não se tomou nenhum cuidado especial com a variável memória. A memória é uma capacidade mental que se combina e se relaciona com outras capacidades, como a linguagem, o raciocínio e a construção de conhecimentos. Ela permite ao ser humano a fixação de informações e sua conseqüente conservação, as ações de reconhecimento e de evocação ${ }^{(13)}$.

Estudo que verificou a habilidade de memória seqüencial verbal mostra que todos os sujeitos avaliados, de três a 12 anos, conseguiram repetir pelo menos duas das três sequiências de três sílabas testadas ${ }^{(14)}$. Assim, acredita-se que aos quatro anos de idade (menor idade avaliada com o TFDF), as crianças não tenham dificuldade para memorizar as duas palavras da apresentação, pois é preciso que elas utilizem apenas a memória de trabalho (curto prazo) para então responderem à tarefa do teste. Lembra-se que cada apresentação é constituída por apenas duas palavras, de no máximo três sílabas cada.

Considera-se positivo o uso de motivação verbal ao sujeito testado, pois mantém o interesse do sujeito no teste, instigando-o a continuar desempenhando bem as tarefas. Também, pelo fato de que as expectativas da criança quanto ao seu desempenho frente à tarefa, influenciam grandemente o seu desempenho. Por este motivo, no TFDF será permitido o uso de expressões para encorajar e motivar a criança.

Os dados qualitativos mostram fatores específicos do desempenho de cada criança, que auxiliam na interpretação dos dados quantitativos, na compreensão do comportamento da criança, na revisão da qualidade do teste utilizado. Assim, na avaliação do TFDF serão considerados também os aspectos qualitativos do desempenho da criança.

Sabe-se que o ambiente de teste merece atenção especial. Essa atenção diz respeito à presença de estímulos de distração, ao conforto da criança testada, à presença de iluminação suficiente, a um ambiente silencioso. Estes cuidados são fundamentais para garantir o bom desempenho do sujeito no teste ou, pelo menos, para excluir que o mau desempenho tenha sido causado por fatores alheios ao sujeito testado. Assim, serão especificados detalhes do ambiente de teste para a aplicação do TFDF.

\section{RESULTADOS}

A seguir, apresenta-se os resultados desta pesquisa. Estes resultados estão dispostos em subtítulos para facilitar o entendimento do leitor.

\section{Seleção das oposições de fonemas e dos pares mínimos}

As oposições possíveis entre os traços distintivos com valores binários encontradas foram: [+soante] e [-soante]; [+aprox] e [-aprox]; [+cont] e [-cont]; [+voz] e [-voz]; e as combinações possíveis entre os traços de lugar foram: [labial] e [cor]; [cor] e [dorsal]; [labial] e [dorsal]; [cor+ant] e [cor-ant]. Os traços [+soante] e [-soante] e [+aprox] e [-aprox] têm diferenças de classe principal. Os demais pares de traços distintivos têm diferenças de classe não principal.

O Quadro 1 mostra estas oposições de traços distintivos, os representantes de fonemas para cada um destes traços e os 
pares de fonemas que se opõem somente nos traços distintivos em questão.

A única exceção vista no quadro é o par $/ \mathrm{r} / \mathrm{x} / \mathrm{z} /$, referente à oposição [+aprox] x [-aprox]. Este par se opõe por dois traços distintivos. Mesmo assim foi incluído no TFDF porque não foi possível encontrar pares mínimos para o par de fonemas /r/ x /1/ que atendessem aos quesitos descritos na metodologia.

A partir dos dados do Quadro 1 e dos critérios de seleção dos pares mínimos descritos na metodologia selecionaram-se os pares mínimos que compõem o TFDF. Estes pares podem ser visualizados no Quadro 2.

No Português Brasileiro, as estruturas silábicas mais comuns são as seguintes: V, CV, CVC, CCV. Para contrastar estas estruturas entre si era necessário encontrar pares de palavras, contendo os mesmos fonemas arranjados de forma diferente, dentro das seguintes oposições: $\mathrm{V}$ x CV; CVC x CCV; CV x CVC; CV x CCV.

Não foi possível encontrar palavras que representassem a oposição de estrutura silábica CVC x CCV e, ao mesmo tempo, atendessem os critérios de escolha dos pares. Encontraram-se os seguintes pares de palavras com estas estruturas: furta $\mathrm{x}$ fruta; garça x graça; parto x prato. Contudo, as palavras: furta, garça e parto não são comuns ao vocabulário da maioria das crianças com quatro anos; além disso, seria difícil ilustrar as palavras furta, graça e parto. Por isso, esta oposição de estrutura silábica não está contemplada no teste. O Quadro 3 apresenta os pares de palavras selecionados para representar a oposição de estruturas silábicas.

\section{Uso de figuras}

Criou-se 68 figuras a partir dos pares mínimos do TFDF e das palavras dos itens de demonstração. Estas figuras foram dispostas em cartelas. Para cada apresentação do TFDF, são utilizadas três cartelas: uma contém duas vezes a figura que ilustra a palavra A; outra contém duas vezes a figura que ilustra

Quadro 1. Seleção dos pares de fonemas a partir da oposição de traços distintivos

\begin{tabular}{|c|c|c|}
\hline $\begin{array}{l}\text { Traços distintivos a serem } \\
\text { opostos }\end{array}$ & Fonemas que representam estes traços & $\begin{array}{l}\text { Fonemas que se opõem somente } \\
\text { por estes traços }\end{array}$ \\
\hline [+soante] $\times$ [-soante] & $\begin{array}{l}\text { [+soante]: /m/, /n/, /ñ/, /l/, /K /, /r/, /R/ } \\
\text { [-soante]: /p/, /b/, /t/, /dd/, /k/, /g/, /f/, /v/, /s/, /z/, /š/, /žl }\end{array}$ & $\begin{array}{l}/ \mathrm{m} / \times / \mathrm{b} / \\
/ \mathrm{n} / \times / \mathrm{d} /\end{array}$ \\
\hline [+aprox] x [-aprox] & $\begin{array}{l}\text { [+aprox]: ///, /K /, /r/, /R/ } \\
\text { [-aprox]: todos os outros fonemas. }\end{array}$ & $\begin{array}{l}/ \mathrm{l} / \mathrm{x} / \mathrm{n} / \\
/ \mathrm{r} / \mathrm{x} / \mathrm{z} /{ }^{*}\end{array}$ \\
\hline$[+$ cont $] \times[$-cont $]$ & 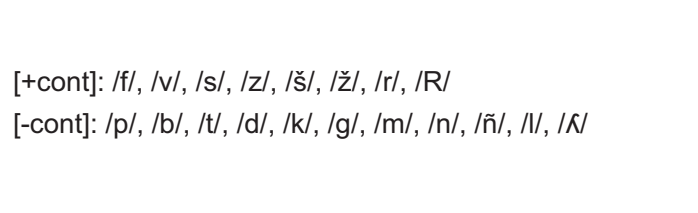 & $\begin{array}{l}/ \mathrm{f} / \times / \mathrm{p} / \\
/ \mathrm{v} / \times / \mathrm{b} / \\
/ \mathrm{s} / \times / \mathrm{t} / \\
/ \mathrm{z} / \times / \mathrm{d} / \\
/ / / \times / \mathrm{r} /\end{array}$ \\
\hline$[+\mathrm{voz}] \times[-\mathrm{voz}]$ & 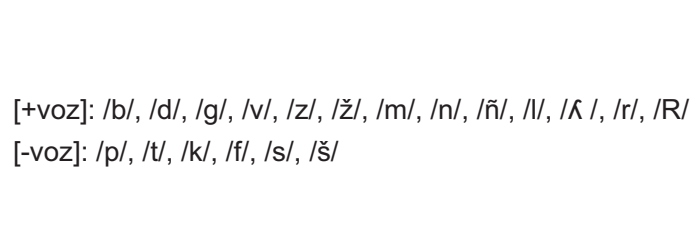 & $\begin{array}{l}/ \mathrm{p} / \times / \mathrm{b} / \\
/ \mathrm{t} / \times / \mathrm{d} / \\
/ \mathrm{k} / \times / \mathrm{g} / \\
/ \mathrm{f} / \times / \mathrm{v} / \\
/ \mathrm{s} / \times / \mathrm{z} / \\
/ \mathrm{s} / \times / \mathrm{z} /\end{array}$ \\
\hline [cor] [+ ant] x [-ant] & 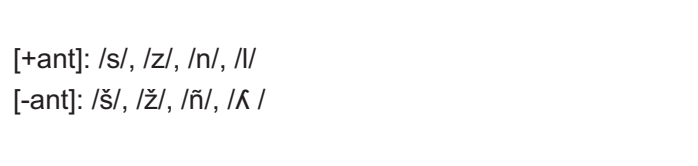 & $\begin{array}{l}/ \mathrm{s} / \times / \mathrm{s} / \\
\mid \mathrm{z} / \times / \mathrm{z} / \\
/ \mathrm{n} / \times / \tilde{n} / \\
/ I / \times / K /\end{array}$ \\
\hline [labial] x [coronal] & $\begin{array}{l}\text { [labial]: /p, /b/, /ff/, /v/, /m/ } \\
\text { [cor]: /t/, /d/, /s/, /z/, /šs/, /žl, /n/, /ñ /, /I/, / /N/, /r }\end{array}$ & $\begin{array}{l}/ \mathrm{p} / \times / \mathrm{t} / \\
/ \mathrm{b} / \times / \mathrm{d} / \\
/ \mathrm{f} / \times / \mathrm{s} / \\
/ \mathrm{v} / \times / \mathrm{z} / \\
/ \mathrm{m} / \times / \mathrm{n} /\end{array}$ \\
\hline [cor] x [dorsal] & $\begin{array}{l}\text { [cor]: /t/, /d/, /s/, /z/, /š/, /žl, /n/, /ñ/, /I/, /K/, /r/ } \\
\text { [dorsal]: /k/, /g/, /R/ }\end{array}$ & $\begin{array}{l}/ \mathrm{k} / \times / \mathrm{t} / \\
/ \mathrm{g} / \times / \mathrm{d} / \\
/ \mathrm{R} / \times / \mathrm{r} /\end{array}$ \\
\hline [labial] x [dorsal] & $\begin{array}{l}\text { [labial]: /p, /b/, /ff/, /v/, /m/ } \\
\text { [dorsal]: /k/,/g/, /R/ }\end{array}$ & $\begin{array}{l}/ \mathrm{k} / \times / \mathrm{p} / \\
/ \mathrm{g} / \times / \mathrm{b} /\end{array}$ \\
\hline
\end{tabular}

* os fonemas $/ \mathrm{r} / \mathrm{x} / \mathrm{z} /$ opõem-se por dois traços distintivos [+soante] [-soante] e [+aprox] [-aprox].

Legenda: aprox = aproximante; cont = contínuo; cor = coronal; ant = anterior 
Quadro 2. Pares mínimos selecionados para constituírem o teste

\begin{tabular}{|c|c|c|c|c|c|c|}
\hline $\begin{array}{c}\text { Traços distintivos } \\
\text { contrastados }\end{array}$ & $\begin{array}{c}\text { Fonemas que } \\
\text { fazem a oposição }\end{array}$ & $\begin{array}{c}\mathrm{N}^{\circ} \text { de traços } \\
\text { distintivos } \\
\text { diferentes }\end{array}$ & Pares mínimos & $\mathrm{N}^{\circ}$ de sílabas & Tipo onset & Estrutura silábica \\
\hline +/-soante & $/ \mathrm{m} / \mathrm{x} / \mathrm{b} /$ & 1 & $\begin{array}{c}\text { mar } x \text { bar } \\
\text { mala } x \text { bala } \\
\text { cabelo } x \text { camelo }\end{array}$ & $\begin{array}{l}1 \\
2 \\
3\end{array}$ & $\begin{array}{l}\text { OI } \\
\text { OI } \\
\text { OM }\end{array}$ & $\begin{array}{l}\text { CVC } \\
\mathrm{CV} \\
\mathrm{CV}\end{array}$ \\
\hline +/-aproximante & $|r / x / z|$ & 2 & cara x casa & 2 & OM & CV \\
\hline +/-contínuo & $\begin{array}{l}/ \mathrm{f} / \mathrm{x} / \mathrm{p} / \\
/ \mathrm{z} / \mathrm{x} / \mathrm{d} / \\
/ \mathrm{s} / \mathrm{x} / \mathrm{t} /\end{array}$ & $\begin{array}{l}1 \\
2 \\
2\end{array}$ & $\begin{array}{c}\text { filha x pilha } \\
\text { rosa x roda } \\
\text { praça x prata }\end{array}$ & $\begin{array}{l}2 \\
2 \\
2\end{array}$ & $\begin{array}{l}\text { OI } \\
\text { OM } \\
\text { OM }\end{array}$ & $\begin{array}{l}\mathrm{CV} \\
\mathrm{CV} \\
\mathrm{CV}\end{array}$ \\
\hline +/-voz & $\begin{array}{l}/ \mathrm{b} / \times / \mathrm{p} / \\
/ \mathrm{z} / \times / \mathrm{s} / \\
/ \mathrm{d} / \times / \mathrm{t} / \\
/ \mathrm{f} / \times / \mathrm{v} / \\
/ \mathrm{z} / \times / \mathrm{s} /\end{array}$ & $\begin{array}{l}1 \\
1 \\
1 \\
1 \\
1\end{array}$ & $\begin{array}{c}\text { bomba x pomba } \\
\text { queixo x queijo } \\
\text { quadro x quatro } \\
\text { faca } x \text { vaca preço } \\
\text { x preso }\end{array}$ & $\begin{array}{l}2 \\
2 \\
2 \\
2 \\
2\end{array}$ & $\begin{array}{l}\text { Ol } \\
\text { OM } \\
\text { OM } \\
\text { OI } \\
\text { OM }\end{array}$ & $\begin{array}{l}\mathrm{CV} \\
\mathrm{CV} \\
\mathrm{CCV} \\
\mathrm{CV} \\
\mathrm{CCV}\end{array}$ \\
\hline coronal+ant/-ant & $\begin{array}{l}/ \mathrm{l} / \mathrm{x} / \mathrm{K} / \\
/ \mathrm{n} / \mathrm{x} / \tilde{\mathrm{n}} /\end{array}$ & $\begin{array}{l}1 \\
1\end{array}$ & $\begin{array}{l}\text { vela } \times \text { velha } \\
\text { galo } \times \text { galho } \\
\text { sono } \times \text { sonho }\end{array}$ & $\begin{array}{l}2 \\
2 \\
2\end{array}$ & $\begin{array}{l}\text { OM } \\
\text { OM } \\
\text { OM }\end{array}$ & $\begin{array}{l}\mathrm{CV} \\
\mathrm{CV} \\
\mathrm{CV}\end{array}$ \\
\hline labial/coronal & $\begin{array}{l}/ \mathrm{p} / \times / \mathrm{t} / \\
/ \mathrm{v} / \times / \mathrm{z} /\end{array}$ & $\begin{array}{l}1 \\
1\end{array}$ & $\begin{array}{l}\text { porta } \text { x torta } \\
\text { cavar } \times \text { casar }\end{array}$ & $\begin{array}{l}2 \\
2\end{array}$ & $\begin{array}{c}\text { OI } \\
\text { OM }\end{array}$ & $\begin{array}{l}\text { CVC } \\
\text { CVC }\end{array}$ \\
\hline dorsal/coronal & $\begin{array}{l}/ \mathrm{r} / \times / \mathrm{R} / \\
/ \mathrm{d} / \times / \mathrm{g} /\end{array}$ & $\begin{array}{l}1 \\
1\end{array}$ & $\begin{array}{c}\text { careta } \times \text { carreta } \\
\text { dado } \times \text { gado }\end{array}$ & $\begin{array}{l}3 \\
2\end{array}$ & $\begin{array}{l}\text { OM } \\
\text { OI }\end{array}$ & $\begin{array}{l}\text { CV } \\
\text { CV }\end{array}$ \\
\hline dorsal/labial & $\begin{array}{l}/ \mathrm{p} / \times / \mathrm{k} / \\
/ \mathrm{b} / \mathrm{x} / \mathrm{g} /\end{array}$ & $\begin{array}{l}1 \\
1 \\
1\end{array}$ & $\begin{array}{c}\text { sapo x saco } \\
\text { espada x escada } \\
\text { pano x cano } \\
\text { bola } \times \text { gola }\end{array}$ & $\begin{array}{l}2 \\
3 \\
2 \\
2\end{array}$ & $\begin{array}{l}\text { OM } \\
\text { OM } \\
\text { OI } \\
\text { Ol }\end{array}$ & $\begin{array}{l}\mathrm{CV} \\
\mathrm{CV} \\
\mathrm{CV} \\
\mathrm{CV}\end{array}$ \\
\hline
\end{tabular}

Legenda: $\mathrm{OI}=$ onset inicial; $\mathrm{OM}=$ onset medial; CVC = consoante-vogal-consoante; CV = consoante-vogal; CCV = consoante-consoantevogal

Quadro 3. Pares de palavras selecionados para representar a oposição de estrutura silábica

\begin{tabular}{|c|c|c|}
\hline $\begin{array}{c}\text { Estruturas Silábicas } \\
\text { Contrastadas }\end{array}$ & Par Mínimo & $\mathrm{N}^{\circ}$ de Sílabas \\
\hline V x CV & ovo x povo & 2 \\
& uva x luva & 2 \\
\hline CV x CCV & banco $x$ branco & 2 \\
& pato x prato & 1 \\
\hline CV x CVC & fio x frio & 2 \\
& pote $x$ poste & 2 \\
\hline
\end{tabular}

Legenda: $\mathrm{V}=$ vogal; $\mathrm{CV}=$ consoante-vogal; $\mathrm{CCV}=$ consoanteconsoante-vogal; CVC = consoante-vogal-consoante.

a palavra B e outra contém as figuras que ilustram as palavras A e B, não necessariamente nesta ordem, para evitar que a criança deduza um padrão de resposta. As cartelas possuem um número e uma letra no verso; o número indica a apresentação e as letras indicam a ordem em que as cartelas devem ser posicionadas (por exemplo: 1A, 1B, 1C). Um exemplo de cartelas do TFDF pode ser visualizado no Anexo 1 deste artigo.

\section{Itens de demonstração}

Foram incluídos no teste quatro itens de demonstração.
Dois deles apresentam simplesmente duas palavras com a mesma extensão silábica (três e uma sílabas respectivamente), mas que não formavam pares mínimos (cavalo x boneca, pão x trem). Estas palavras foram escolhidas por serem conhecidas das crianças e de fácil representação em desenho. Os outros dois itens de demonstração foram compostos igualmente por duas palavras de mesma extensão silábica (três e duas sílabas, respectivamente), mas dessa vez, por pares mínimos (corrida $\mathrm{x}$ comida, gata $\mathrm{x}$ lata).

\section{Número de apresentações}

Após as reflexões descritas na metodologia e a seleção de pares mínimos, conjuntamente com a elaboração das figuras que os representam, chegou-se à versão do TFDF apresentada neste artigo. Assim, o Teste de Figuras para a Discriminação Fonêmica (TFDF) foi composto por 30 pares mínimos (60 palavras) listados nos Quadros 2 e 3 e por quatro itens de demonstração. Esses pares mínimos foram organizados em 40 apresentações, das quais 30 são apresentações com duas palavras diferentes e dez são apresentações com duas palavras iguais. As apresentações com duas palavras iguais foram incluídas no teste para fazer com que a criança que for submetida a ele preste mais atenção. Se houvesse somente apresentações com palavras diferentes no teste, após algumas apresentações a criança poderia deduzir que todas as respostas apresentam 
um padrão, ou seja, ela deve mostrar a cartela com duas figuras diferentes; e passaria a apontar para esta cartela sem nem mesmo prestar atenção auditiva às palavras faladas. Os dez pares de palavras iguais distribuem-se de tal forma pelo teste, que cinco estejam entre as 20 primeiras apresentações e cinco entre as 20 apresentações finais.

Das 30 apresentações com duas palavras diferentes, três diferenciam-se pela oposição [+/-soante], uma pela oposição [+/-aproximante], três por [+/-contínuo], cinco por [+/-voz], três pela oposição [coronal+/-anterior], duas por [labial] $\mathrm{x}$ [coronal], duas por [dorsal] x [coronal]; quatro por [dorsal] x [labial] e sete pela oposição de estruturas silábicas, das quais duas diferem por $\mathrm{V}$ x CV, duas por CV x CVC e três $\mathrm{CV}$ x CCV. A ordem das apresentações obedece a esta mesma seqüência. Para as apresentações de duas palavras iguais escolheram-se aqueles pares com palavras simples e cuja representação em desenho é de fácil acesso para as crianças.

Observa-se que, em relação à posição de onset (inicial ou medial) do fonema contrastado, apenas não se conseguiu representantes de ambas as posições quando se contrastou o traço [+aprox] [-aprox], com os fonemas /r/ e /z/. Isto ocorreu pela impossibilidade estrutural da língua que proíbe o /r/ nesta posição ${ }^{(8)}$. Lembra-se que na oposição [cor+ant] e [cor-ant] não seria possível a posição de onset inicial, já que os fonemas $/ K /$ e /ñ/ não aparecem nesta posição no Português Brasileiro.

\section{Composição do TFDF}

A versão do TFDF apresentada neste artigo compõe-se por 132 cartelas ilustradas, um Manual de Aplicação, um Protocolo de Apresentação e um Protocolo de Respostas. O Manual de Aplicação encontra-se no Anexo 2 e explica os procedimentos do teste. Antes de iniciá-lo, o examinador deve verificar se as cartelas estão na ordem correta.

O Protocolo de Apresentação contém as ordens verbais que devem ser dadas às crianças, quando não houver gravação das apresentações em CD-ROM. Estas ordens devem ser lidas de maneira clara, observando-se a articulação correta dos fonemas. O examinador deve segurar o Protocolo de Apresentação em frente à sua boca para eliminar as pistas visuais da articulação dos fonemas. Para facilitar o manuseio por parte do examinador, deixou-se em negrito as apresentações com palavras repetidas. No Anexo 3, encontram-se alguns exemplos do Protocolo de Apresentação.

As respostas das crianças deverão ser anotadas no Protocolo de Respostas (Anexo 4).

\section{DISCUSSÃO}

A seguir serão discutidos os resultados apresentados, confrontando-os com a literatura pesquisada. Esta discussão também está dividida em subtítulos para melhor compreensão do leitor.

\section{Tipo de estímulo}

Em relação ao tipo de estímulo usado para testar a discriminação fonêmica, a Prova para Avaliar a Discriminação
Auditiva $^{(6)}$ usa pares de sílabas, e o Teste de Figuras para Discriminação Auditiva ${ }^{(7)}$ usa pares mínimos.

No TFDF foram utilizados pares mínimos. Acredita-se que este seja o melhor estímulo para avaliar esta habilidade, já que utiliza palavras com significado. O par mínimo contorna a influência da sobrearticulação, pois o contexto fonológico é semelhante para ambas as palavras do par, e por usar palavras, possui o aspecto dinâmico da cadeia de fala. Além disso, a palavra com significado evita a dispersão da atenção à discriminação fonêmica, por não exigir atenção da criança examinada na busca por acesso léxico (o que não é o caso de palavras ou sílabas sem significado).

\section{Faixa etária a ser avaliada}

O TFDF deve ser aplicado em crianças que tenham acima de quatro anos, pois a partir desta idade, a maioria das crianças já adquiriu todos os fonemas do Português Brasileiro ${ }^{(15)}$. A idade de oito anos foi considerada limite para ser avaliada pelo TFDF porque se acredita, a partir da experiência clínica das autoras, que a maioria das crianças que procuram atendimento fonoaudiológico o fazem até esta idade. Também, o vocabulário utilizado no TFDF foi pensado para crianças que estivessem dentro dessa faixa de idades.

\section{Oposição de traços distintivos}

Tanto a Prova para Avaliar a Discriminação Auditiva( ${ }^{(6)}$ como o Teste de Figuras para Discriminação Auditiva ${ }^{(7)}$ usaram oposição de fonemas nas sílabas/pares estímulos, escolhidos com base na impressão clínica de maior ocorrência de trocas na fala das crianças com problemas de linguagem. No TFDF, optou-se por opor fonemas baseados na oposição do valor binário de seus traços distintivos, ou na oposição dos traços de lugar.

Utilizou-se a oposição de traços distintivos pelo fato de serem estes as menores unidades em que podem ser subdivididos os fonemas da língua, e por serem os responsáveis pela sua diferenciação ${ }^{(9)}$.

\section{Uso de figuras}

Em relação ao uso de figuras nos testes, as elaboradoras do CONFIAS- Consciência Fonológica: Instrumento de Avaliação Seqüencial $^{(11)}$ utilizam figuras correspondentes às palavrasmodelo em alguns itens do teste para auxiliar a memória das crianças e obter um instrumento lúdico.

Na proposição do teste AFC-Avaliação Fonológica da Criança ${ }^{(9)}$, os autores dizem que a utilização de desenhos é o meio mais adequado para a eliciação da nomeação espontânea. Ainda, podem ser utilizados desenhos isolados ou temáticos, sendo que os desenhos isolados tendem a eliciar unicamente palavras isoladas, enquanto que os temáticos levam à produção das palavras-chave e conduzem também a narrações e descrições.

Para o objetivo da $\mathrm{AFC}^{(9)}$, os desenhos temáticos foram considerados mais adequados, pois os autores necessitavam de uma grande amostra de fala das crianças avaliadas. Já para o objetivo do TFDF, acredita-se que o uso de figuras isoladas 
seja o mais adequado, pois facilita o processo de busca rápida o acesso ao léxico da palavra ouvida, enquanto que uma figura temática poderia dificultar este processo, exigindo uma análise mais demorada.

\section{Itens de demonstração}

No CONFIAS ${ }^{(11)}$, antes da tarefa a ser realizada, estão presentes sempre dois exemplos iniciais, com o intuito de verificar se as crianças a serem avaliadas entenderam a tarefa que deverão realizar. Se a criança a ser testada não compreender bem a tarefa com estes dois exemplos, o avaliador deve dar a resposta correta, fornecendo explicações adicionais.

No Protocolo de Tarefas de Consciência Fonológica ${ }^{(12)}$ também se indicou o uso de dois treinos antes de cada tarefa do teste, com o objetivo de deixar claro o significado do que era proposto para que a criança não tivesse o processo de elaboração da resposta prejudicado por questões de semântica.

Na Prova para Avaliar a Discriminação Auditiva ${ }^{(6)}$, também se encontra uma pré-prova, para explicar o que se pretendia de resposta da criança.

Assim, acredita-se que a inclusão de itens de demonstração no TFDF vai ao encontro do que vários autores de testes criados para avaliar diversas áreas da linguagem acreditam.

\section{Número de apresentações/Tempo de aplicação}

Na Prova para Avaliar a Discriminação Auditivaa ${ }^{(6)}$ foi utilizada uma gravação para a apresentação dos estímulos auditivos. Com isto, o autor conseguiu padronizar o tempo de aplicação do teste em três minutos e 30 segundos. Lembra-se que esta prova é composta por 30 pares de sílabas.

No Teste de Figuras para Discriminação Auditiva( ${ }^{(7)}$, são usados 25 apresentações. Em relação ao tempo de aplicação, as autoras do CONFIAS ${ }^{(11)}$ enfatizam que ele deve ser aplicado em duas sessões para evitar a fadiga.

Acredita-se que o número de apresentações de um teste, por influenciar diretamente no tempo de aplicação, não deve ser muito grande, evitando o mau desempenho conseqüente ao cansaço da criança testada. Assim, supõe-se que o número de 40 apresentações do TFDF pode ser considerado apropriado para a faixa etária a que se propõe a avaliar, pois não deixará o teste exaustivo ou demasiadamente demorado.

\section{Pistas visuais}

No Teste de Figuras para Discriminação $\operatorname{Auditiva}^{(7)}$, o examinador deve tampar a boca na hora de apresentar os pares de palavras para evitar uso da leitura labial por parte das crianças examinadas. Já na Prova para Avaliar a Discriminação Auditi$\mathrm{va}^{(6)}$, espera-se que com o uso da gravação para a apresentação dos estímulos, impeça-se o uso de pistas visuais por parte da criança testada, já que o estímulo é somente auditivo. Nesta prova, o examinador deve considerar a resposta errada, caso a criança utilize apoio tátil-cinestésico antes de responder às apresentações, ou se repetir à viva-voz as sílabas ouvidas.

Concorda-se com a literatura pesquisada em relação ao cuidado para evitar o uso de pistas visuais por parte da criança. Acredita-se que este cuidado permite controlar que a discriminação feita pela criança testada seja baseada apenas no estímulo auditivo. Por isso, durante a apresentação do TFDF, o avaliador deve tapar a boca usando o Protocolo de Apresentação.

\section{Motivação verbal ao sujeito testado}

Na Prova para Avaliar a Discriminação Auditiva( ${ }^{(6)}$ é permitido aos examinadores adotarem atitudes de aprovação para as respostas corretas da criança durante a pré-prova, para motivá-la a ter uma boa atitude durante a prova. No entanto, o examinador não deve se manifestar no caso de respostas incorretas, bem como durante o teste em si.

A autora do Protocolo de Tarefas de Consciência Fonológi$\mathrm{ca}^{(12)}$ enfatiza que as ordens a serem dadas pelo examinador às crianças em testes de consciência lingüística devem ser o mais simples possível, para evitar dificuldades em sua compreensão, envolvendo muito a memória e a cognição e prejudicando o desempenho na tarefa.

Concorda-se que as ordens dadas às crianças devem ser simples e, por isso, a exemplo da autora do Protocolo de Tarefas de Consciência Fonológica ${ }^{(12)}$ também utilizar-se-á o termo "jogo" e não "teste" para referir-se ao TFDF no momento da aplicação. Mas discorda-se da posição adotada pelo autor da Prova para Avaliar a Discriminação Auditiva, de que o examinador não deve se manifestar durante a aplicação do teste. Por isso, no TFDF, o examinador poderá manifestar-se com expressões de encorajamento, para motivar a criança a continuar.

\section{Ambiente de Testagem}

Aspectos importantes devem ser observados em relação ao ambiente de teste. As idealizadoras do ABFW - Teste de Linguagem Infantil nas Áreas de Fonologia, Vocabulário, Fluência e Pragmática ${ }^{(16)}$, ressaltam que o ambiente de aplicação do teste deve ser adequado, com privacidade, bem iluminado e sem fatores de distração ou estressantes. Sobre a mesa de testagem deverá estar apenas o material a ser usado no teste. Esses cuidados potencializarão a qualidade dos resultados encontrados.

Com base nestes cuidados, elaborou-se o item 1 do Manual de Aplicação do TFDF (ver resultados). Concorda-se que o ambiente de teste deve ser adequado, bem iluminado, com a criança posicionada confortavelmente, sem estímulos de distração.

\section{Avaliação qualitativa}

A análise qualitativa do desempenho da criança envolve a observação do desempenho específico de cada criança e dos comentários por ela formulados durante a aplicação do instrumento $^{(11)}$. Por isto, incluiu-se no TFDF uma parte para anotar e avaliar o desempenho qualitativo da criança testada.

\section{CONCLUSÃO}

Acredita-se que o objetivo desta pesquisa foi alcançado com êxito, uma vez que se propôs o Teste de Figuras para Dis- 
criminação Fonêmica - TFDF. Este teste conseguiu abranger todos os fonemas do português brasileiro, alguns mais representados (como /b/, /z/, /p/, que aparecem em 4, 4 e 5 exemplos respectivamente) e outros menos representados (como /š/, /žl, $/ K /, \tilde{\mathrm{n}} /, / \mathrm{n} /, / \mathrm{R} /$ que aparecem em apenas um exemplo). Não foi possível balancear o número de apresentações por oposição de traços distintivos e por fonemas porque se buscou seguir fielmente os critérios de escolha das palavras, quais sejam: fazer parte do vocabulário das crianças na faixa etária proposta; ser facilmente representável por figura e usar de duas posições nas palavras (OI e OM) e nem sempre se encontrou palavras que atendessem a estes critérios.

Entende-se que o TFDF tenha alcançado um caráter lúdico e informal, pela presença de figuras e pela forma como é estruturado. É de fácil aplicação, não é demorado, não tem muitas exigências em relação ao ambiente de teste, utiliza-se de pouco material. E o mais importante: avalia a habilidade de discriminação fonêmica de uma maneira adequada, pois opõe os fonemas da língua, considerando sua menor unidade constitutiva, os traços distintivos. Esta oposição ocorre em palavras, o que aproxima a habilidade de discriminação fonêmica, necessária para a realização das tarefas propostas pelo teste de uma situação mais real do processamento lingüístico dinâmico da cadeia de fala.

Conclui-se que o TFDF é um instrumento que poderá ser amplamente utilizado nos diversos ambientes de trabalho do fonoaudiólogo (clínicas, escolas, postos de saúde, etc.), auxiliando este profissional no fechamento do diagnóstico das alterações fonoaudiológicas e no delineamento da terapia. Igualmente, acredita-se que este será um instrumento útil para as pesquisas científicas na área.

Considera-se necessária a realização de um estudo piloto, onde o TFDF seja aplicado para averiguar se as palavras escolhidas, bem como as figuras do teste, estão adequadas à faixa etária que ele se propõe a avaliar.

Salienta-se que, para que isto seja possível, é necessário padronizar o TFDF para a população brasileira, para que se possa saber o que é esperado como desempenho normal para a maioria da população brasileira, na faixa etária dos quatro aos oito anos.

Sugere-se, assim, para pesquisas futuras, que o TFDF seja aplicado em uma amostra considerável da população brasileira e em diversas regiões deste país, para que ele possa ser padronizado.

\title{
ABSTRACT
}

\begin{abstract}
Purpose: To propose a test to evaluate phonemic discrimination using minimum pairs, comprising all Brazilian Portuguese phonemes and using them in words which can be easily represented by pictures. The purpose of this test was to contribute to the diagnosis of phonologic alterations and to scientific research on this field. The proposed test was easy to apply and to be used in any workplace. Methods: It was selected minimum pairs that opposed phonemes in relation to the binary value of each distinctive trait and to the possible combinations among the position traits ([labial], [coronal], [dorsal]) as well as by the oppositions of syllabic structure. Pictures representing the words of the pairs were created. Results: The Phonemic Discrimination Picture Test (PDPT) was set up to evaluate the ability of auditory phonemic discrimination in children ranging from four to eight years old. The test consists of 40 presentations: 30 minimum pairs and 10 pairs of equal words. In the 30 minimum pairs presentations, the distinctive traits [+/- sonant], [+/- closing], [+/-continuous], [+/- voice], [coronal+/-ant], [labial x coronal], [dorsal] x [coronal] and [labial] x [dorsal] were opposed. The following syllabic structures were equally opposed: V x CV, CV x CCV, CV x CVC. Conclusion: The aims of the present study were successfully reached, given that PDPT accomplishes what it was proposed to do. Further, the test should be used in a pilot study in order to examine whether its words and pictures are adequate to the age range it is supposed to evaluate. Afterwards, it must be applied in children from several regions of the country to be properly standardized.
\end{abstract}

KEYWORDS: Speech discrimination tests; Speech perception; Language development; Child language; Language development disorders

\section{REFERÊNCIAS}

1. Magalhães ATM, Paolucci JF, Ávila CRB. Estudo fonológico e da percepção auditiva de crianças com ensurdecimento de consoantes. Fono Atual. 2006;8(35):22-9.

2. Leonard LB, McGregor KK, Allen GD. Grammatical morphology and speech perception in children with specific language impairment. J Speech Hear Res. 1992;35(5):1076-85.

3. Rvachew S. Speech perception training can facilitate sound production learning. J Speech Hear Res. 1994;37(2):347-57.

4. Wolfe V, Presley C, Mesaris J. The importance of sound identification training in phonological intervention. Am J Speech Lang Pathol. 2003;12(3):282-8.

5. Ribas A. A influência do meio social sobre o desenvolvimento da percepção auditiva em crianças. J Bras Fonoaudiol. 2001;2(8):224-8.

6. Rodrigues EJB. Discriminação auditiva: normas para avaliação de crianças de 5 a 9 Anos. São Paulo: Cortez Editora: Autores Associados; 1981.

7. Mota HB, Keske-Soares M, Vieira MG. Teste de figuras para discriminação auditiva. Adaptado do The Boston University Speech Sound Discrimination Picture Test. Santa Maria: CELF/SAF Universidade Federal de Santa Maria; 2000.

8. Mota HB. Aquisição segmental do português: um modelo implicacional de complexidade de traços. Letras Hoje. 1997;32(4):23-47.

9. Yavas MS, Hernandorena CLM, Lamprecht RR. Avaliação fonológica da criança: reeducação e terapia. Porto Alegre: Artes Médicas; 1992. 
10. Clements GN, Hume E. The internal organization of speech sounds. In: Goldsmith JA, editor. Handbook of phonological theory. Cambridge, Mass., USA: Blackwell; c1996. p. 245-306.

11. Moojen S, coordenador. CONFIAS - Consciência fonológica: instrumento de avaliação seqüencial. São Paulo: Casa do Psicólogo; 2003.

12. Cielo CA. Habilidades em consciência fonológica em crianças de 4 a 8 anos de idade. (Tese Doutorado). Porto Alegre: Faculdade de Letras da Pontifícia Universidade Católica do Rio Grande do Sul; 2001.
13. Linassi LZ, Keske-Soares M, Mota HB. Habilidades de memória de trabalho e o grau de severidade do desvio fonológico. Pro-Fono. 2005;17(3):383-92.

14. Corona AP, Pereira LD, Ferrite S, Rossi AG. Memória seqüencial verbal de três e quatro sílabas em escolares. Pro-Fono. 2005;17(1):27-36.

15. Alabarse VM, Wertzner HF. Estudo de caso: avaliação e tratamento de um sujeito com alterações fonológicas. Pro-Fono. 1998;10(1):86-91.

16. Andrade CRF, Lopes DMB, Fernandes FDM, Wertzner HF. ABFW: teste de linguagem infantil nas áreas de fonologia, vocabulário, fluência e pragmática. Barueri: Pró-Fono; 2002.
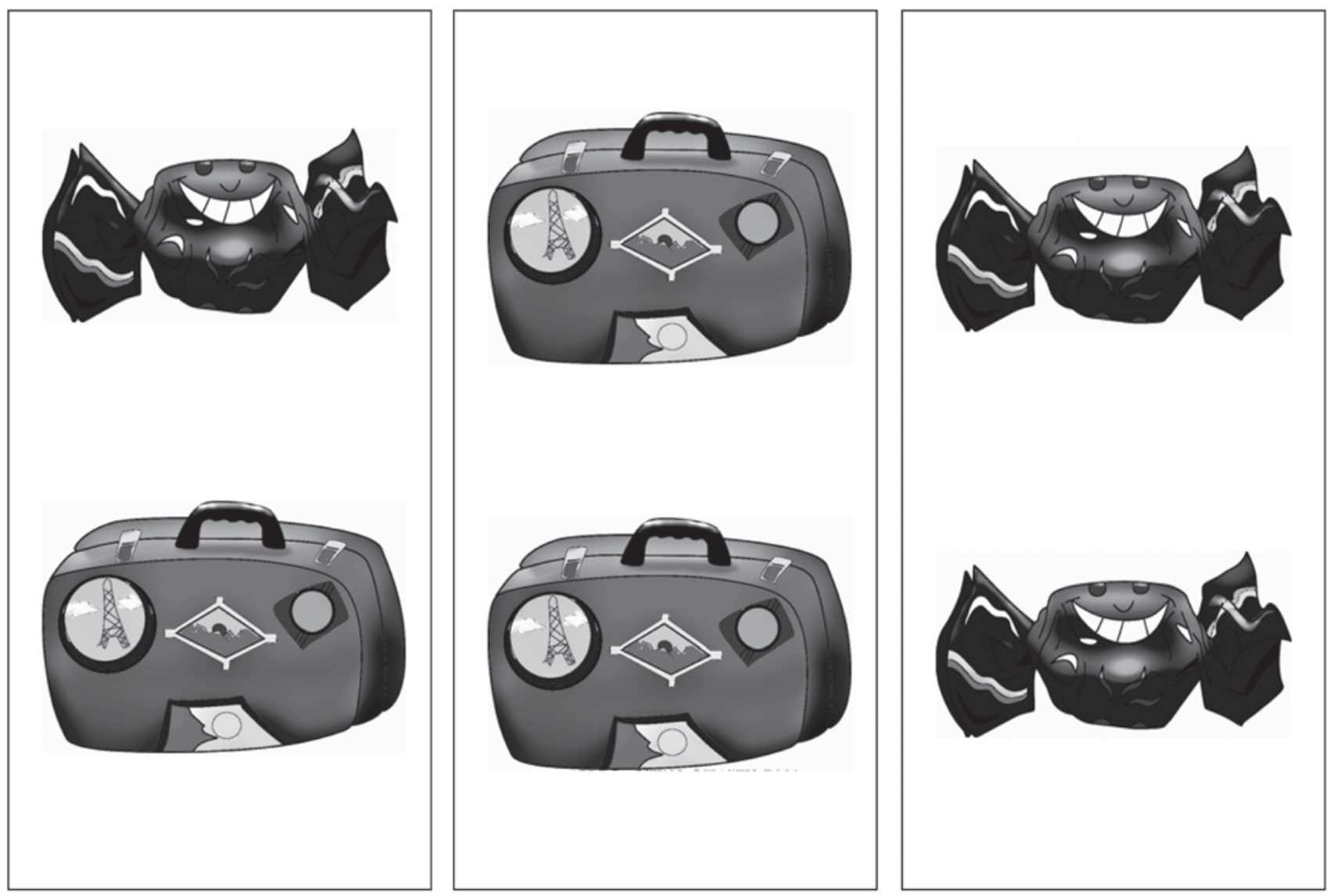
Anexo 2. Manual de aplicação do TFDF

1- O teste deve ser aplicado em um local silencioso, para evitar interferências do ruído nas respostas das crianças. Não devem ser deixados brinquedos, revistas ou livrinhos perto do local de aplicação do teste para não desviar a atenção da criança. A criança deve estar sentada confortavelmente, numa altura adequada para ter uma boa visão das cartelas de apresentação do TFDF dispostas sobre a mesa.

2- Antes de iniciar a avaliação, o examinador deve verificar se as cartelas do teste estão na ordem correta, bem como se o Protocolo de Apresentação e de Respostas estão em cima da mesa.

3- O examinador não deve utilizar o termo "teste" quando for explicar à criança o que será feito. Ele pode convidar a criança para jogar um "jogo de adivinhação". Então, explicará à criança que serão colocadas sobre a mesa três cartelas com figuras. Ela ouvirá uma ordem pedindo que mostre a cartela que contém esta e aquela figura. Em seguida, deverá apontar para a cartela que contém as figuras citadas. Com crianças menores (quatro, cinco anos) pode-se iniciar colocando as cartelas da primeira apresentação dos itens de demonstração na frente da criança e perguntar que figuras ela está vendo. Então solicitar à criança que mostre a figura A (ex: a boneca). Depois pedir que mostre a figura $B$ (ex: cavalo). Em seguida, pedir que mostre a cartela que tem as figuras $A$ e $B$.

4- Caso o examinador perceba que a criança não compreendeu a tarefa durante as apresentações dos itens de demonstração, deve fornecer as respostas corretas e dar explicações adicionais. As respostas da criança às apresentações dos itens de demonstração nunca contam para a pontuação.

5- As apresentações devem ser lidas pelo examinador e repetidas somente uma vez se assim for solicitado pela criança. Caso a criança peça uma segunda repetição, o examinador poderá repetir a apresentação para evitar frustração por parte da criança, mas anotará no Protocolo de Respostas uma observação citando o fato, e desconsiderará a resposta dada pela criança à apresentação.
6- O examinador do TFDF não deverá confirmar à criança se a sua resposta foi correta. Pode, entretanto, usar de algumas expressões de encorajamento ou elogios para motivar a criança a continuar. Expressões como: "que criança esperta!", "continue assim..." ou "ótimo!" podem ser utilizadas no decorrer do teste.

7- As respostas da criança devem ser marcadas no Protocolo de Respostas que acompanha o TFDF. O examinador deverá evitar anotar as respostas de forma que a criança as visualize. Para isso, pode colocar o Protocolo de Respostas no colo, colocá-lo sobre a mesa e escondê-lo com o Protocolo de Apresentações ou utilizar uma mesa que tenha um gaveteiro móvel. Caso a criança aponte as figuras corretas, porém, situadas em cartelas diferentes o examinador deve considerar certa a resposta e explicar à criança novamente que as figuras devem aparecer na mesma cartela. No Protocolo de Respostas há espaço para realizar anotações relevantes no decorrer da aplicação do teste para posterior análise qualitativa do desempenho da criança. Não devem ser consideradas erradas respostas que utilizem apoio articulatório ou que sejam feitas após repetição oral do par da apresentação por parte da criança.

8- A análise qualitativa implica em observar os comentários e reações da criança durante a aplicação do teste, bem como a apreciação de fatores de desempenho específico de cada criança, como: interesse, concentração, fadiga, dificuldades de compreensão da tarefa, utilização de apoio articulatório para realização da discriminação fonêmica, solicitação de explicações extras, respostas que mostrem sempre uma cartela na mesma posição ou um determinado padrão de respostas (mostra sempre uma cartela que contenha dois desenhos iguais ou diferentes, ou então sempre a cartela do meio, por exemplo).

9- A pontuação do teste será efetuada somando-se um ponto para cada resposta correta e zero ponto para respostas incorretas ou provenientes de segunda repetição da apresentação, totalizando um máximo de 40 pontos.

Anexo 3. Protocolo de apresentação TFDF (Exemplos)

\section{Itens de demonstração:}

1-Mostre a cartela onde estão a boneca e a boneca.

2-Mostre a cartela onde estão o pão e o trem.

3-Mostre a cartela onde estão a comida e a corrida.

4-Mostre a cartela onde estão a lata e a lata.

\section{Apresentações do TFDF:}

1- Mostre a cartela onde estão a mala e a mala.

2- Mostre a cartela onde estão o mar e o bar.

3- Mostre a cartela onde estão o cabelo e o camelo

4- Mostre a cartela onde estão a mala e a bala.

5- Mostre a cartela onde estão a cara e a casa. 
Anexo 4. Protocolo de respostas do TFDF

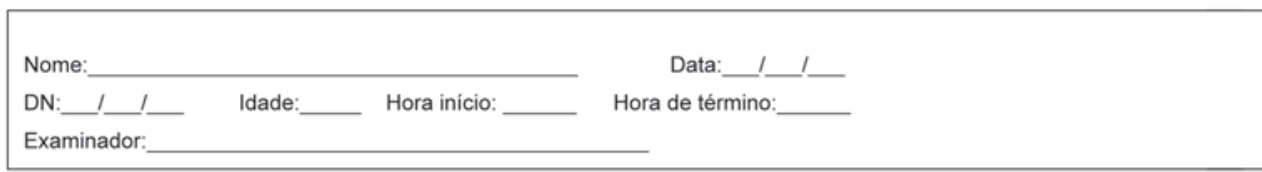

\begin{tabular}{|c|c|c|c|c|}
\hline \multirow{2}{*}{$\begin{array}{l}\text { Oposição de traço distintivo/ Estrutura } \\
\text { silábica }\end{array}$} & \multirow{2}{*}{$\begin{array}{l}\text { Apresentação - } \\
\text { Par mínimo }\end{array}$} & \multicolumn{3}{|c|}{ Resposta } \\
\hline & & A & B & $\mathrm{C}$ \\
\hline \multirow{4}{*}{ [+/-soante] } & 1- mala x mala & & & \\
\hline & 2-mar $\times$ bar & & & \\
\hline & 3- cabelo x camelo & & & \\
\hline & 4-mala $\times$ bala & & & \\
\hline [+/-aproximante] & 5-cara $\times$ casa & & & \\
\hline \multirow{4}{*}{ [+/-contínuo $]$} & 6- praça $\times$ prata & & & \\
\hline & 7-rosa $\times$ roda & & & \\
\hline & 8-cabelo $x$ cabelo & & & \\
\hline & 9-filha $x$ pilha & & & \\
\hline \multirow{7}{*}{ [+/-voz] } & 10-bomba x pomba & & & \\
\hline & 11- filha $x$ filha & & & \\
\hline & 12- queixo x queijo & & & \\
\hline & 13-quadro $\times$ quatro & & & \\
\hline & 14-faca $\times$ vaca & & & \\
\hline & 15- preço $\times$ preso & & & \\
\hline & 16- torta $\times$ torta & & & \\
\hline \multirow{4}{*}{ [coronal+/-anterior] } & $17-$ vela $\times$ velha & & & \\
\hline & 18- galo $\times$ galho & & & \\
\hline & 19- sono $\times$ sonho & & & \\
\hline & 20- quadro $x$ quadro & & & \\
\hline \multirow{2}{*}{$\begin{array}{l}\text { Oposição de traço distintivo/ Estrutura } \\
\text { silábica }\end{array}$} & \multirow{2}{*}{$\begin{array}{l}\text { Apresentação - } \\
\text { Par minimo }\end{array}$} & \multicolumn{3}{|c|}{ Resposta } \\
\hline & & A & B & C \\
\hline \multirow[b]{4}{*}{ [labial] x [coronal] } & 21-porta $\times$ torta & & & \\
\hline & 22- cavar $x$ casar & & & \\
\hline & 23- pata $\times$ pata & & & \\
\hline & 24- bola $\times$ bola & & & \\
\hline \multirow[b]{2}{*}{ [dorsal] x [coronal] } & 25- carreta $\times$ careta & & & \\
\hline & 26 - dado $\times$ gado & & & \\
\hline \multirow{5}{*}{ [dorsal] x [labial] } & 27-sapo x saco & & & \\
\hline & 28- bola $\times$ gola & & & \\
\hline & 29- cano $\times$ pano & & & \\
\hline & 30-prato $\times$ prato & & & \\
\hline & 31- escada $x$ espada & & & \\
\hline \multirow{3}{*}{$\mathrm{V} \times \mathrm{CV}$} & 32- uva x luva & & & \\
\hline & 33- ovo x povo & & & \\
\hline & 34-carreta $\times$ carreta & & & \\
\hline \multirow[b]{2}{*}{$\mathrm{CV} \times \mathrm{CVC}$} & 35- pote $\times$ poste & & & \\
\hline & 36-pata x pasta & & & \\
\hline \multirow{4}{*}{$\mathrm{CV} \times \mathrm{CCV}$} & 37- pato $\times$ prato & & & \\
\hline & 38-sapo x sapo & & & \\
\hline & 39-banco $\times$ branco & & & \\
\hline & 40- fio $\times$ frio & & & \\
\hline
\end{tabular}

PONTUAÇÃO:

pontos

ANÁLISE QUALITATIVA: 